\title{
Nesting Island Creation for Wading Birds ${ }^{1}$
}

\author{
C. Leann White, Peter C. Frederick, Martin B. Main, and James A. Rodgers, Jr. ${ }^{2}$
}

\section{Introduction}

Many long-legged wading birds such as little blue herons (Egretta caerulea), great blue herons (Ardea herodius), and great egrets (Ardea albus) nest together in large aggregations called breeding colonies. Although different species vary in their habitat preferences, wading birds have several common requirements for nesting. Colony sites must provide protection from predators, nesting materials, and nearby foraging areas (Hafner 2000). In the past, wading birds nested in natural wetland habitats that are becoming increasingly scarce as wetland habitats are continually altered or degraded to accommodate human needs. The future success of wading bird populations may be determined by how well they cope with manipulated foraging and nesting habitats. Here, we make recommendations on the creation of nesting islands for long-legged wading birds.

\section{The decision to create a nesting island}

Creation of a nesting island can be an expensive, long-term venture with numerous benefits and drawbacks, many of which depend on the social values of the creators and the local residents.
Benefits of creating a nesting island include providing important nesting habitats for threatened or declining species; offering visitors a rare chance to observe colonial nesting by large, colorful wading birds; serving as a focus for environmental and conservation education or ecotourism; and acting as a draw for other species that are part of the ecological community. The drawbacks include the potential for noise and offensive smells from the nesting colony and increased numbers of human visitors to view the spectacle. Furthermore, if sited near aquaculture facilities, the birds may be viewed as pests and create a local conflict.

Local acceptance of the colony by humans is an important first step in long-term success and sustainability of the colony. There are also some important biological factors to be considered if the colony is to be judged a success. Wading birds typically rely on foraging areas tens of kilometers away from the colony. Therefore, the following questions should be considered and discussed with conservation and natural resource personnel prior to constructing a nesting island:

- Is the proposed colony site within range of good foraging areas?

1. This document is Circular 1473, one of a series of the Wildlife Ecology and Conservation Department, Florida Cooperative Extension Service, Institute of Food and Agricultural Sciences, University of Florida. Published: May 2005. Please visit the EDIS Web site at http://edis.ifas.ufl.edu.

2. C. LeAnn White, graduate student; Peter C. Frederick, Research Associate Professor; Martin B. Main, associate professor and extension wildlife specialist; Wildlife Ecology and Conservation Department, University of Florida/IFAS, Gainesville, FL. James A. Rodgers, Jr., biological administrator, Florida Fish and Wildlife Conservation Commission, Gainesville, FL.

The Institute of Food and Agricultural Sciences (IFAS) is an Equal Opportunity Institution authorized to provide research, educational information and other services only to individuals and institutions that function with non-discrimination with respect to race, creed, color, religion, age, disability, sex, sexual orientation, marital status, national origin, political opinions or affiliations. U.S. Department of Agriculture, Cooperative Extension Service, University of Florida, IFAS, Florida A. \& M. University Cooperative Extension Program, and Boards of County Commissioners Cooperating. Larry Arrington, Dean 
- Is there any history of colonies in the area?

- Are there appropriate wetlands within $10 \mathrm{~km}$ of the site?

- Is the site close to aquaculture facilities, hatcheries, or other areas in which the birds may be regarded as pests?

-Will the birds be attracted to local landfills or other sites where toxic or harmful materials might become available to them?

The degree of human disturbance to the colony may also be of concern. If the colony is located in an area frequented by recreational boaters, it may be difficult to keep the curious and the devious from disturbing the birds to the point that the colony is abandoned.

Considering these types of issues prior to construction will help increase the likelihood that a created island will be accepted by humans and used by waterbirds. However, it should also be kept in mind that waterbirds are highly mobile species and they are not always faithful to a particular nesting site year after year. Therefore, if you decide to create a nesting island, it may be one of many colony sites used by waterbirds in your region, which may mean some years with few or no nesting birds.

Furthermore, it may take several breeding seasons for the birds to locate and use a newly created nest island.

\section{Nesting Habitat Requirements}

\section{Predator protection - the moat}

Most wading birds nest in woody vegetation either submerged or surrounded by water (Ogden, 1991; Rodgers et al., 1996). Water is essential for nesting colonies because it provides a safety buffer against land predators such as raccoons (Procyon lotor) and rats (Rattus sp.). These animals typically eat or destroy nest contents rather than kill the adult birds. Wading birds have no behavioral defenses to medium and large mammals and are at a severe disadvantage when faced with nocturnal mammal predators. A small number of these mammals can devastate an entire wading bird colony by destroying nests and eating eggs and chicks or by causing adult birds to abandon the colony (Beaver et al., 1980; Rodgers, 1987).

There may be several means by which water surrounding the colony serves as a barrier to mammals. Although many mammals can swim quite well, large expanses of water present a very real energetic expense. In addition, mammals may be at risk of predation, either by large fish and sharks in salt water, or by alligators (Alligator mississippiensis) in fresh water. There may in fact be a mutual benefit for alligators and wading birds to associate at colonies: the wading birds get protection from mammals, and the alligators consume spilled food and young birds that fall out of the nests. Indeed, wading birds seem to be attracted to places with alligators; they have nested directly inside heavily visited tourist attractions where large numbers of alligators or other crocodilians patrol the water (e.g., St. Augustine Alligator Farm, St. Augustine, Florida).

Islands may be preferred nesting sites by many species of wading birds. The Florida Fish and Wildlife Conservation Commission (FWCC) found that about three quarters of colonies in Florida were located on islands (Figure 1).

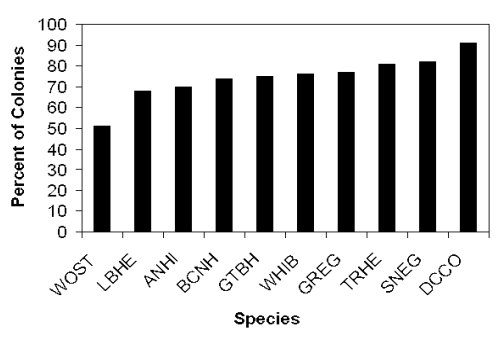

Figure 1. Percentage of colonies in Florida located on islands for 10 species of wading birds. Data were collected by the Florida Fish and Wildlife Conservation Commission in 1999. (http://wildflorida.org/waders, date accessed 3/1/04). Analyzed data included only those species for which $>10$ colonies were observed and species identification accuracy was medium to high.

Although there are many factors that may alter the ability of small mammals to gain access to an island, we recommend that minimum distances from the island to the "mainland" be at least $50 \mathrm{~m}$, and larger distances are preferable. Water depths surrounding the colony should be at least $0.5 \mathrm{~m}$ during the December-July breeding season in south Florida 
and the March-August season in north Florida and the southeast United States.

\section{Management of water levels and nutrients for sustainable vegetation}

Another consideration for providing predator protection for wading bird nesting sites is the stability of water levels surrounding the colony. Water levels in natural wetlands vary seasonally and annually. These fluctuations can influence predation rates in wading bird colonies by allowing predators to walk to nest sites if the soft-bottom substrate is exposed. Created nesting islands that maintain water levels of at least $0.5 \mathrm{~m}$ during droughts and dry seasons may become particularly valuable to populations of waterbirds during years of low rainfall. If colony vegetation is continuously flooded, however, establishing new vegetation may become difficult (Rodgers et al., 1996). One way around this problem is to create islands that maintain vegetation at elevations higher than the surrounding water (Figure 2).

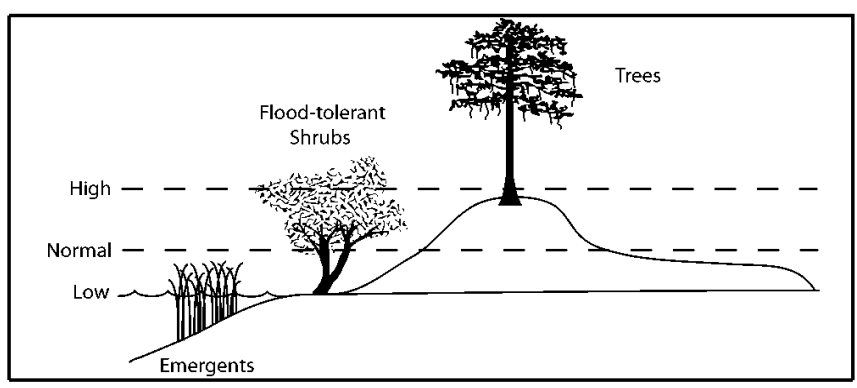

Figure 2. Diagram of created nest island for waterbirds illustrating examples of various annual water levels and vegetation tolerant of the different inundation levels. (Figure created by Matthew J. Reetz)

A potential problem with establishing vegetation on a nesting island is that the accumulation of bird feces may kill vegetation through acidification of the soil. One way to remove nutrients is to allow water to inundate the island vegetation on a regular basis, such as once a year for two months or twice a year for a month each. Most woody plants that tolerate water will not be damaged by inundation for even up to six months of the year, and the fluctuating water levels can serve to remove the buildup of guano from the soil. The elevation difference need not be very great: a two-foot difference between low and high water should be enough to aerate roots of the plants during the dry phase. In addition, the island can be constructed with a sloped surface, so that plants with a variety of inundation tolerances can be used (Figure 2). Some vegetation such as cypress (Taxodium spp.) and maples (Acer spp.) are quite tolerant of acidic soil, and planting these types of trees may help make island vegetation more sustainable. Ultimately, however, most colony vegetation is likely to suffer from guano deposition due to the very high nutrient levels if there is no way to remove those nutrients, so natural inundation or artificially raising the surrounding water levels will be necessary to maintain island vegetation.

Other potential problems associated with large amounts of guano include smells that may be objectionable to local residents. Guano can also alter the surrounding waters by increasing their nutrient loads and may create algal blooms. The specific effects of the nutrients will depend on the characteristics of the water bodies, with smaller, shallower water bodies seeing greater effects. Annual flushing, aeration, or other creative management solutions such as growing large amounts of macrophytic vegetation to absorb nutrients and then removing them regularly from the surface of the water may help reduce the nutrient loads.

\section{Types of woody vegetation}

Wading birds nest in trees and shrubs. The type of tree or shrub is probably less important than its ability to support adult birds and their nests (Beaver et al., 1980). The comprehensive use of a variety of woody vegetation by wading birds simplifies our choice of nesting vegetation to include a variety of species that suit local soil types and water levels. One consideration, however, is the growth rate for various tree species. Because it can take years for slower growing species such as bald or pond cypress (Taxodium distichum) to grow large enough to be used by larger wading birds (e.g., wood storks, Mycteria americana), newly created nest sites may need to have a mixture of fast and slow growing trees and shrubs. Examples of fast growing species include red maple (Acer rubrum), southern bayberry (Myrica cerifera), dahoon holly (Ilex cassine), and willow (Salix spp.). Slower growing trees such as oaks and bald or pond cypress provide the strong limbs required by larger nesting birds such as great blue 
herons, great egrets, and wood storks. Artificial nest structures might also work, particularly for larger species, to supplement nesting vegetation and attract birds to newly created sites. Artificial nest structures can be as simple as a $4 \times 4$ " post with fence wire mesh and sticks wired to the top. This method has been successful in attracting and maintaining a wood stork colony in coastal Georgia (Figure 3).

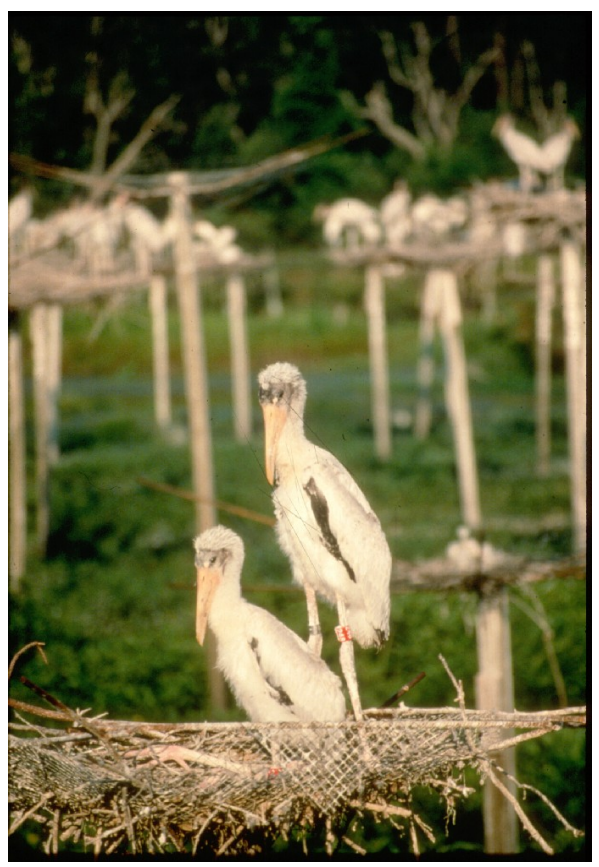

Figure 3. Artificial nest structures constructed from wood posts and wire mesh being used by wood stork nestlings at Harris Neck National Wildlife Refuge in Mclntosh County, Georgia. (Photograph courtesy of Larry Bryan, Savannah River Ecology Laboratory).

Tree limbs or smaller posts attached to the side could be used to provide the birds with perches. Dead trees (snags) may also be attractive landing and nesting sites for wading birds. Although the stability of snags will decrease over time as the wood decomposes, snags may be another means of creating inexpensive nesting substrate for wading birds until planted trees grow large enough to be used.

Within a colony, there are considerable differences in nesting site preference among species (Burger, 1978). In a typical mixed-species colony, one might find great egrets and great blue herons nesting in the tops of the tallest trees or shrubs; snowy egrets (Egretta thula), little blue herons, and tricolored herons (Egretta tricolor) nesting under the canopy in shaded or partly shaded conditions; white ibises (Eudocimus albus) nesting in a variety of sub-canopy locations including grasses or even dry ground; and glossy ibises (Plegadis falcinellus) on the ground or in grass clumps. For this reason, a variety of vegetation types that creates a variety of vertical strata and shading is critical to attracting a full component of species. Local experts should be consulted to determine the types of vegetation most suitable for different regions.

Another vegetation requirement for nest sites is the availability of adequate materials to construct nests. Materials that must be available within the site or near the colony include small branches, sticks, fine twigs, and thick-stemmed grasses that are frequently used in nest construction (Hafner, 2000). In general, smaller waterbirds use smaller materials (e.g., fine twigs) to build their nests. In order to assure adequate materials year after year, the colony-site should be located near (i.e., within about $0.25 \mathrm{mi}$; however, some birds may travel further) vegetated areas with live and dead material. Nesting materials can also be provided at the colony site directly, using woody refuse containing the materials mentioned above. For example, a very successful artificial colony for great egrets created in the 1930s was supplied with bamboo cuttings (McIlhenny, 1934).

\section{Set-back distances from disturbance}

Wading bird colonies can be impacted by human disturbance. Disturbance early in the breeding season can influence the decision to nest. Later in the season, disturbance can flush adult birds, leaving eggs and nestlings unattended and vulnerable to predators, or can result in premature fledging. Vulnerability to disturbance varies among wading bird species. Therefore, buffer zones or set-back distances to reduce disturbances during the nesting season should be based on the most sensitive species nesting in the colony (see Rodgers and Smith, 1995). In general, the nesting islands should be located at least $100 \mathrm{~m}$ from shore in areas of human activity. However, if a $100-\mathrm{m}$ buffer distance is not possible for the created island, there may be other possible alternatives (e.g., vegetation barriers with tall emergence or shrubs to prevent direct visual contact with the colonies; Rodgers and Smith, 1995). In addition, although the $100-\mathrm{m}$ buffer is recommended, there are many 
characteristics that may modify the ability of birds to tolerate human disturbance. For example, as above, the colonies that formed in the dense alligator attractions did so in extremely close proximity to very heavy human visitation (hundreds of visitors daily at $2-20 \mathrm{~m}$ from nests). Apparently, the consistent nonintrusive behavior of the humans, their restriction to boardwalks, and the presence of the alligators was enough to negate any effects of disturbance. A colony that is separated by a large water buffer from regular land-based human disturbance, but that is irregularly subjected to close approaches by boats, may suffer greatly from periodic disturbance.

\section{Shallow and deep water areas}

While colonies should be surrounded by water at least $0.5 \mathrm{~m}$ deep during the nesting season, there is also a need for shallow water areas on the island edge. Nest island construction should include a very shallow $(5-20 \mathrm{~cm})$ area that extends $5-30 \mathrm{~m}$ into the water in selected areas around the island. This habitat enhancement has two major benefits for the nesting birds. First, it will promote the growth of emergent vegetation that will help to visually screen the island and provide seclusion. Second, shallow areas provide young birds an area to learn how to forage and capture prey. However, shallow water areas tend to be colonized quickly by emergent vegetation and will most likely require maintenance to thin the vegetation and keep these areas attractive to foraging wading birds.

\section{Island size and shape}

Islands 2-10ha in area may be used more often than very large or very small islands (Erwin et al., 1995). Large islands are not used if mammals are able to reach them or when they support a population of nest-predators year-round. Alternatively, very small islands may be unable to support adequate amounts of vegetation for large numbers of birds or may not attract enough birds to form a critical social mass for nesting. Larger islands can support more abundant and diverse populations of wading birds, but creating islands greater than 10ha is not usually logistically feasible for most created habitats. Therefore, the rule of thumb should be to create as large a colony as possible without compromising other habitat requirements (e.g., set-back distances).
There does not seem to be any clear preference of birds for islands of different shapes, so long as the area and vegetation are appropriate. However, shape might be used to increase viewing opportunities for humans (long, skinny islands), further buffer birds from human disturbance (round islands with low edge-to-area ratios), or to create shallow foraging opportunities where fledglings can learn to forage (doughnut-shaped; Figure 4).
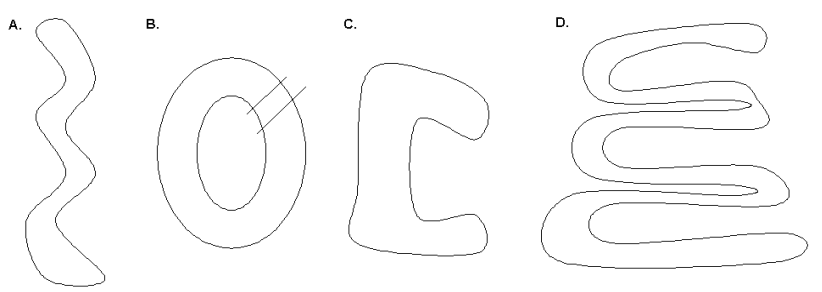

Figure 4. Examples of shapes for constructed waterbird nesting islands: A. Sinuous and skinny would provide increased edge effect needed for visibility of predators by the birds. B. Doughnut-shaped would provide more edge than a solid circular shape while maintaining a low-disturbance area in the center. A canal would allow water to inner area to prevent problems associated with stagnant water (e.g. mosquito breeding). C. Ear-shaped with vegetated center area would increase the edge-to-area ratio but would allow increased accessibility to maintain vegetation. D. Coil-shaped, which is extremely sinuous and has many loops, would also result in increased edge effect. This shape could easily be created with a dragline or conveyor belt.

\section{Use of bird decoys to attract wading birds}

Most wading birds are social species that forage and nest in groups with other species. This also means that many wading birds use the presence of other wading birds as a cue for suitable habitats. Therefore, once the habitat factors necessary for nesting are in place, bird decoys may be one way to attract birds to a newly created nest island. One type of decoy used successfully by researchers to attract wading birds to a specific location is a set of plastic flamingos that were painted white (Crozier and Gawlik, 2003; Heath and Frederick, 2003), though in this case the attraction was short-lived. If other conditions are right for nesting (woody vegetation, 
adequate nesting materials, presence of water, etc.) this method may increase the likelihood that birds will be attracted to a particular island.

\section{Vegetaion management}

Especially with the abundant fertilizer (guano) typical of wading bird colonies, vegetation will either alternately grow rapidly or begin to die off, and in either case may quickly develop unwanted attributes. Shallow water areas created for foraging fledglings will be rapidly colonized by emergent aquatic vegetation; some trees and shrubs may become too dense for nesting; and some older trees may not replace themselves. Floating aquatic vegetation surrounding the island may become so dense that mammals can safely make their way across from the mainland. For these reasons, it is wise to plan on regular maintenance of the vegetation during the non-breeding season.

\section{Visiting a wading bird colony}

It may be beneficial to visit one or several existing colonies to get a better understanding of what they look like and how they function. One good resource is the Waterbird Colony Locator created by the Florida Fish and Wildlife Conservation Commission from its statewide aerial surveys of waterbird colonies in Florida in 1999. This database can be found online at http://myfwc.com/waders/, where interested persons can locate colonies by county, township/range/section, and/or by species. The information in this database can also be used to determine whether there is a history of waterbird use in a particular area. When visiting, be sure to contact local landowners or resource managers for permission, and if visiting during the nesting season, maintain at least $100 \mathrm{~m}$ between yourself and nesting birds.

\section{Conclusions}

The construction of nest islands is likely to benefit many species of wading birds and may often benefit humans as aesthetic, spiritual, and educational icons. Before construction, consideration should be given to whether the surrounding foraging habitat can support the colony and whether the colony will be accepted by local residents. Educational signs, kiosks, and pamphlets as well as birding tours may help to promote a feeling of goodwill and enthusiasm regarding the presence of nesting colonies on islands. Design considerations for the island include the type of vegetation planted, the distance from the shore, the size and shape of the island, and the water levels or water level fluctuations surrounding the islands. The availability of food is also intricately linked to breeding success in wading birds (Hafner, 2000; Ogden and Nesbitt, 1979), so the creation of nesting sites may be particularly suitable for landscapes that also provide wading bird foraging habitat (e.g., golf courses, see White, 2003). However, each site will be unique. Although the suggestions made in this paper result from the synthesis of many years of observation and scientific investigation, the reader should be aware that there have been few artificial islands built and consultations

\section{Literature Cited}

Beaver, D. L., R. G. Osborn, and T. W. Custer. 1980. Nest-site and colony characteristics of wading birds in selected Atlantic Coast colonies. Wilson Bulletin 92: 200-221.

Burger, J. 1978. The pattern and mechanism of nesting in mixed species heronries. Pages 45-58 in: A. Sprunt, IV, J. C. Ogden, and S. Winkler, editors. Wading Birds. National Audubon Society, New York, New York.

Crozier, G. E., and D. E. Gawlik. 2003. The use of decoys as a research tool for attracting wading birds. Journal of Field Ornithology 74: 53-58.

Erwin, R. M., J. S. Hatfield, and T. J. Wilmers. 1995. The value and vulnerability of small estuarine islands for conserving metapopulations of breeding waterbirds. Biological Conservation 71: 187-191.

Hafner, H. 2000. Heron nest site conservation. Pages 201-217 in: J. A. Kushlan and H. Hafner, editors. Heron Conservation. Academic Press, San Diego, California.

Heath, J. A., and P. C. Frederick. 2003. Trapping white ibises with rocket nets and mist nets in the Florida everglades. Journal of Field Ornithology 74: 187-192. 
McIlhenny, E. 1934. Bird city. Christopher Publishing House, Boston, Massachusetts.

Ogden, J. C. 1991. Nesting by wood storks in natural, altered, and artificial wetlands in central and northern Florida. Colonial Waterbirds 14: 39-45.

Ogden, J. C., and S. A. Nesbitt. 1979. Recent wood stork population trends in the United States. Wilson Bulletin 91: 512-523.

Rodgers, J. A., Jr. 1987. On the antipredator advantages of coloniality: a word of caution. Wilson Bulletin 99: 269-271.

Rodgers, J. A., Jr., and H. T. Smith. 1995. Set-back distances to protect nesting bird colonies from human disturbance. Conservation Biology 9: 89-99.

Rodgers, J. A., Jr., S. T. Schwikert, and A. Shapiro-Wenner. 1996. Nesting habitat of wood storks in north and central Florida, USA. Colonial Waterbirds 19: 1-21.

White, C. L. 2003. Habitat value of created wetlands to waterbirds in golf course landscapes. Thesis, University of Florida, Gainesville, Florida. 